\title{
A Study of Reflected Sonic Booms using Airborne Measurements
}

Samuel R. Kantor and Larry J. Cliatt, II

NASA Armstrong Flight Research Center, Edwards, CA

$$
\text { Abstract }
$$

In support of ongoing efforts to bring commercial supersonic flight to the public, the Sonic Booms in Atmospheric Turbulence (SonicBAT) flight test was conducted at NASA Armstrong Flight Research Center. During this test, airborne sonic boom measurements were made using an instrumented TG-14 motor glider, called the Airborne Acoustic Measurement Platform (AAMP).

During the flight program, the AAMP was consistently able to measure the sonic boom wave that was reflected off of the ground, in addition to the incident wave, resulting in the creation of a completely unique data set of airborne sonic boom reflection measurements. This paper focuses on using this unique data set to investigate the ability of sonic boom modelling software to calculate sonic boom reflections. Because the algorithms used to model sonic boom reflections are also used to model the secondary carpet and over the top booms, the use of actual flight data is vital to improving the understanding of the effects of sonic booms outside of the primary carpet. Understanding these effects becomes especially important as the return of commercial supersonic approaches, as well as ensuring the accuracy of mission planning for future experiments. 